\title{
Leiomioma parauretral: relato de caso
}

\author{
Paraurethral leiomyoma: case report \\ Silmar Cunha da Silva ${ }^{1}$, Indira Barcos Balbino ${ }^{2}$, Maria Eduarda Cristina Teixeira Jordão ${ }^{3}$, \\ Douglas Jun Kamei ${ }^{4}$, Milton Cesar Scaramuzza ${ }^{5}$, Sheldon Rodrigo Botogoski ${ }^{1}$
}

\section{Resumo}

Os leiomiomas parauretral e uretral são raras causas de massas periuretrais, correspondendo a 5 a $7 \%$ dos casos. Os leiomiomas parauretrais apresentam maior incidência em mulheres com idade reprodutiva na $3^{a}$ ou $4^{a}$ década, sendo o crescimento relacionado à presença de hormônios sexuais femininos. Normalmente são assintomáticos quando apresentam pequeno tamanho. A medida em que crescem podem evoluir com infecção do trato urinário, uretrorragia ou hematúria, dispareunia, além de sintomas irritativos e obstrutivos. A seguir, apresentamos um caso de leiomioma parauretral de difícil diagnóstico por apresentação atípica e diversas biópsias discordantes. Foram necessárias várias investigações em diversos hospitais até a resolução do caso. Atribui-se à raridade dessa lesão e sua apresentação atípica a realização do diagnóstico tardio.

Descritores: Leiomioma, Uretra, Neoplasias uretrais

\section{Abstract}

Paraurethral and urethral leiomyomas are rare causes of periurethral masses, corresponding to 5 to $7 \%$ of the cases. Paraurethral leiomyomas have higher incidence in women

1. Preceptores do Serviço de Ginecologia do Hospital Santa Casa de Curitiba (PUCPR)

2. Acadêmica do Curso de Medicina da Pontifícia Universidade Católica do Paraná (PUCPR)

3. Médica Residente do Serviço de Ginecologia e Obstetrícia do Hospital Santa Casa de Curitiba (PUCPR)

4. Médico Residente do Serviço de Urologia do Hospital Santa Casa de Curitiba (PUCPR)

5. Preceptor do Serviço de Urologia do Hospital Santa Casa de Curitiba (PUCPR)

Trabalho realizado: Serviço de Ginecologia e de Urologia do Hospital Santa Casa de Curitiba

Endereço para correspondência: Douglas Jun Kamei. Serviço de Urologia do Hospital Santa Casa de Curitiba (PUCPR). Praça Rui Barbosa, 694 - Centro - Curitiba - PR - Sala da Urologia - 80010030 -Curitiba-PR - Brasil.E-mail:douglaskamei@gmail.com Conflitos de interesse: Não há

Fonte financiadora: Não há

Autorização do paciente: Sim of reproductive age in the 3 rd or 4th decade, with growth related to the presence of female sex hormones. They are usually asymptomatic when small in size. As they grow may progress with urinary tract infection, urethral bleeding or hematuria, dyspareunia, and irritative and obstructive symptoms. The following case is a paraurethral leiomyoma with difficult diagnosis due to atypical presentation and many discordant biopsies. Several investigations were necessary in many hospitals until the resolution of the case. The late diagnosis is attributed to the rarity of this lesion and its atypical presentation.

Keywords: Leiomyoma, Urethra, Urethral neoplasms

\section{Introdução}

O leiomioma é a neoplasia benigna mais comum na mulher, representa $95 \%$ dos tumores do trato genital feminino, sendo responsável por um terço do total de histerectomias. Mulheres entre a $3^{\mathrm{a}}$ e $5^{\mathrm{a}}$ décadas de vida são mais suscetíveis para desenvolver a doença. A neoplasia é mais propensa na raça negra, acometendo $50 \%$ das mulheres, já em mulheres brancas a incidência é de 35\% dos $\operatorname{casos}^{(1)}$. Enquanto os leiomiomas ureterais são observados com frequência, os leiomiomas uretrais e parauretrais são extremamente raros, com poucos casos descritos na literatura. O primeiro caso foi descrito por Buttner em 1894(2).

Neste Relato de Caso é descrito um leiomioma parauretral de difícil diagnóstico por apresentação atípica e diversas biópsias discordantes. Foram necessárias várias investigações em diversos hospitais até a resolução do caso. Atribui-se à raridade dessa lesão e sua apresentação atípica a realização do diagnóstico tardio.

\section{Relato do Caso}

Paciente do sexo feminino, 21 anos, encaminhada ao Serviço de Ginecologia do Hospital da Santa Casa de Curitiba por lesão vegetante parauretral de aproximadamente $3 \mathrm{~cm}$. Apresentava em antecedentes ginecológicos: menarca aos 13 anos, ciclos menstruais irregulares e oligomenorreicos, sexarca aos 18 anos, 
nulípara, sem histórico de doenças sexualmente transmissíveis e uso de métodos contraceptivos.

No início do quadro, relatava ser assintomática, evoluindo com sinusiorragia e sangramento em posição sentada, dispareunia e disúria, associado ao aumento progressivo da lesão. Acompanhou previamente em outros serviços, porém sem definição terapêutica. Inicialmente foi realizada biópsia com identificação de Lesão Intraepitelial de Baixo Grau Condilomatosa (NIVA 1). Em nova biópsia, o estudo histopatológico mostrou inflamação crônica inespecífica de urotélio e extensa área de metaplasia escamosa sem atipias. A cultura e parcial de urina não indicavam presença de infecção bacteriana.

No Hospital Santa Casa de Curitiba a paciente foi submetida à cirurgia conjunta pelos Serviços de Ginecologia e Urologia. A lesão apresentava aproximadamente $3 \mathrm{~cm}$ de diâmetro, de coloração rósea, pediculada e pseudocapsulada. Foi realizada passagem de sonda vesical de demora após identificação do meato uretral e verificação de ausência de acometimento. A seguir foi procedida a exérese completa da lesão (Figuras 1 a 3). A paciente apresentou boa evolução pós-operatória, recebendo alta hospitalar para acompanhamento ambulatorial. Até o momento não foi verificado sinais de recidiva da lesão. A análise anatomopatológica da peça cirúrgica demonstrou proliferação fusiforme compatível com leiomioma. O painel imunhistoquímico indicou expressão de receptores para estrogênio e progesterona positivos.

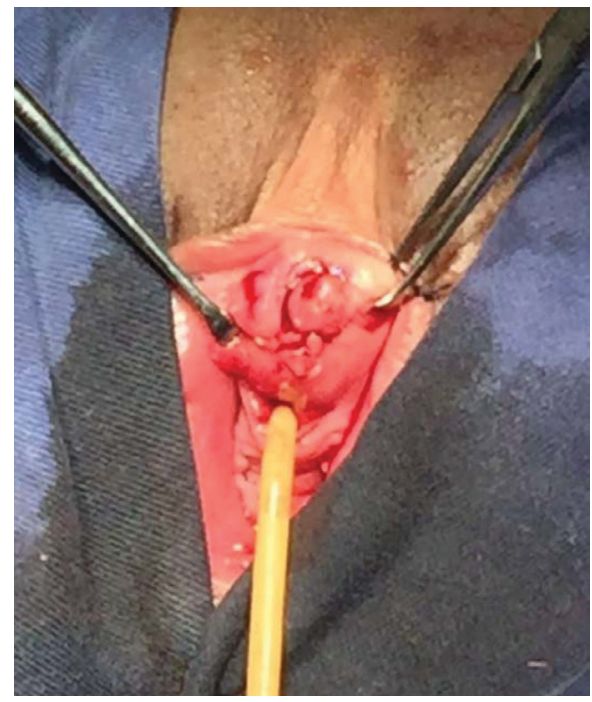

Figura 1 - Identificação do meato uretral e apresentação da lesão (pinça à esquerda).

\section{Discussão}

Os leiomiomas parauretral e uretral são raras causas de massas periuretrais, correspondendo a 5 a $7 \%$

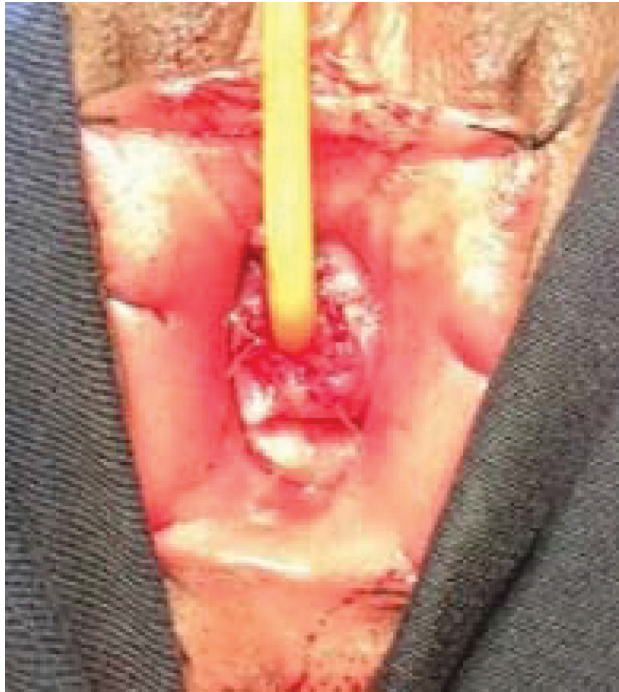

Figura 2 - Aspecto cirúrgico final após exérese da lesão.

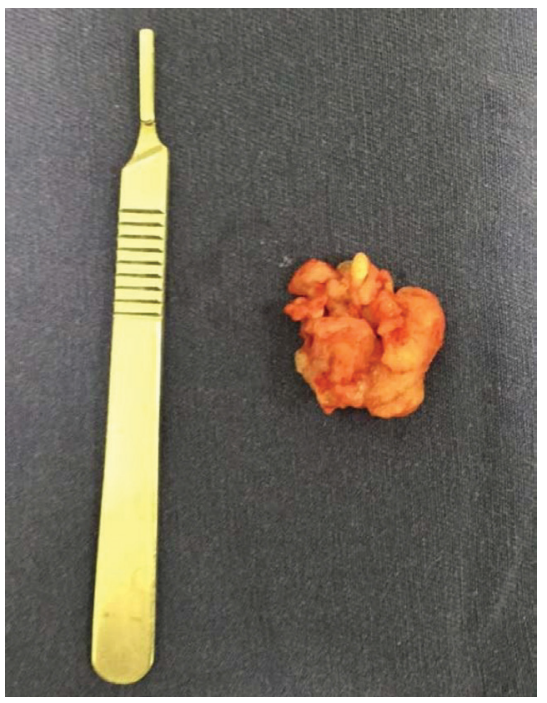

Figura 3 - Aspecto macroscópico da peça cirúrgica.

dos $\operatorname{casos}^{(3)}$. Frequentemente são classificados junto com outras lesões de musculatura lisa do trato urinário baixo. Os leiomiomas parauretrais apresentam maior incidência em mulheres com idade reprodutiva na $3^{\mathrm{a}}$ ou $4^{\mathrm{a}}$ década, sendo o crescimento relacionado à presença de hormônios sexuais femininos ${ }^{(4)}$. A lesão consiste em uma neoplasia mesenquimal nodular de tamanho variável, circunscrita, pseudocapsulada, pediculada ou séssil. Pode ser caracterizada como uma massa brancacenta e endurecida ou rósea de consistência amolecida, cística ou elástica ${ }^{(1,5)}$.

Apesar do fator endocrinológico estar relacionado à gênese do leiomioma, sua etiopatogenia não está totalmente esclarecida. Sabe-se que o fator determinante para o crescimento tumoral é o estradiol, que parece agir diretamente ou mediado por fatores de crescimento como EGF, IGF-1 e insulina, sobre as 
mitoses celulares. O hormônio do crescimento (GH) e o hormônio lactogênio placentário (hPL) possuiriam ação semelhante. A progesterona soma-se ao efeito de inibição da apoptose, pelo aumento da proteína bcl-2 e redução do fator de necrose tumoral ${ }^{(6)}$.

A apresentação clínica varia de acordo com o tamanho e localização tumoral. Os leiomiomas uretrais são normalmente assintomáticos quando apresentam pequeno tamanho. A medida em que crescem, $40 \%$ dos pacientes evoluem com infecção do trato urinário, 28\% apresentam uretrorragia ou hematúria, $20 \%$ queixam-se de dispareunia, além de sintomas irritativos e obstrutivos relacionados ao trato urinário baixo ${ }^{(7)}$. O exame físico pode revelar uma massa próximo à parede vaginal anterior e região uretral ou exteriorizando-se pelo meato uretral ${ }^{(8)}$.

O diagnóstico da massa parauretral baseia-se em uma história detalhada e exame físico minucioso. Caso o diagnóstico não esteja claro ou apresente sinais indicativos de lesões mais complexas, exames de imagem podem ser empregados. A ressonância magnética oferece melhores detalhes a respeito do trato urinário inferior, já a ultrassonografia abdominal ou transvaginal pode apresentar acurácia limitada para lesões distais. A presença de malignidade nas lesões parauretrais é incomum, porém em caso de lesões sólidas, a realização de biópsia pode oferecer informações adicionais e permitir adequado planejamento cirúrgico. No caso em questão, foi optado pela remoção cirúrgica completa da lesão ${ }^{(3)}$.

Em relação aos leiomiomas uretrais, pode-se fazer uso da uretrocistoscopia, uretrocistografia retrógrada e estudo urodinâmico. A uretrocistoscopia avalia a mucosa uretral proximal e vesical, a uretrocistografia retrógrada pode evidenciar defeito de preenchimento uretral, já a avaliação urodinâmica pode indicar aumento da pressão detrussora, associado a resíduo pós-miccional e resistência uretral elevada. Outros diagnósticos diferenciais incluem uretrocele, divertículo uretral e carúncula uretral ${ }^{(9)}$.

O tratamento do leiomioma parauretral é cirúrgico, através da excisão completa da lesão, para evitar recidiva local. Nos leiomiomas de uretra proximal, opta-se pela ressecção transuretral, já nos tumores de localização distal ou parauretral é realizada a excisão local ${ }^{(10)}$. A diferenciação do leiomioma uretral do parauretral é determinada pela possibilidade da remoção dessa última sem rompimento das camadas mucosa e muscular uretral. O prognóstico desse tipo de tumor é excelente, sem relatos descritos de transformação maligna ou recorrência local ${ }^{(11)}$. Entre as possíveis complicações pós-operatórias encontram-se a incontinência urinária de esforço e a estenose uretral ${ }^{(10)}$.

\section{Conclusão}

O leiomioma parauretral é uma rara lesão benigna de difícil diagnóstico, obtido através da avaliação clínica e do estudo anatomopatológico e imunohistoquímico. A diferenciação do leiomioma parauretral do uretral é importante para o planejamento cirúrgico, podendo ser realizados exames complementares de imagem. $\mathrm{O}$ tratamento consiste na exérese completa da lesão, sendo um procedimento seguro, porém não isento de complicações. O conhecimento da anatomia da uretra é necessário para excisão da lesão e possibilidade de reconstrução.

\section{Referências}

1. Urbanetz AA, coordenador. Ginecologia e obstetrícia: FREBASGO para o médico residente. Barueri: Manole; 2016. 1552p.

2. Buttner. [A case of myoma of the female urethra]. Z Geburshe Gynak. 1894; 28:135. (In German)

3. Adams-Piper E, Jacobs S, Ghoniem GM. Paraurethral leiomyoma in a 20-year-old woman: A case report. Urol Case Rep. 2016; 4:14-6.

4. Bergüm $\mathrm{O}$, Charles B. Urethral and paraurethral leiomyomas in the female patient. Int Urogynecol J. 2006;17(1):93-5.

5. Dewis R. Te Linde: atlas de cirurgia ginecológica. São Paulo: Revinter; 2016. 360p.

6. Speroff L, Fritz, MA. Endocrinologia ginecológica clínica e infertilidade. $8^{\mathrm{a}}$ ed. São Paulo: Revinter, 2015. 1498p.

7. Leung YL, Lee F, Tam PC. Leiomioma of the female urethra causing acute urinary retention and acute renal failure. J Urol. 1997; 158(5):1911-2.

8. Shen YH, Yang K. Recurrent huge leiomyoma of the urethra in a female patient: a case report. Oncol Lett. 2014; 7(6): 1933-5.

9. Goto K, Orisaka S, Kurokawa T, Miyazaki M, Kotsuji F. Leiomyoma of the female urethra: Urodynamyc changes after surgical intervention. Int Urogynecol J Pelvic Floor Dysfunct. 2005;16(2):162-4.

10. Lopes SP, Severo L, Gameiro CD, Vilas-Boas V, Forte P, Oliveira $\mathrm{M}$, et al. Leiomioma da uretra feminina. Revisão da literatura a propósito de um caso clínico. Acta Urol. 2009; 26(3):63-6.

11. Pahwa M, Saifee $Y$, Pahwa AR, Gupta M. Leiomyoma of the female urethra: a rare tumor: Case report and review of the literature. Case Rep Urol. 2012; 2012:280816.

Trabalho recebido: $27 / 06 / 2017$

Trabalho aprovado: 17/09/2017 